NISTIR 7193

\title{
Workshop to Define Information Needed by Emergency Responders during Building Emergencies
}

\author{
Walter W. Jones \\ David G. Holmberg \\ William D. Davis \\ David D. Evans \\ Steven T. Bushby \\ Kent A. Reed
}




\section{Workshop to Define Information Needed by Emergency Responders during Building Emergencies}

Walter W. Jones William D. Davis

David D. Evans

Fire Research Division Building and Fire Research Laboratory Gaithersburg, Maryland 20899

David G. Holmberg

Steven T. Bushby

Kent A. Reed

Building Environment Division Building and Fire Research Laboratory Gaithersburg, Maryland 20899

January 2005

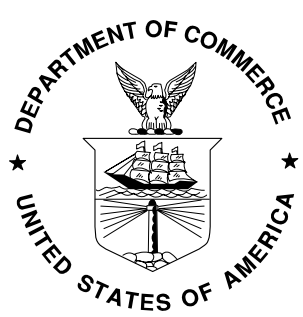

U.S. DEPARTMENT OF COMMERCE

Carlos M. Gutierrez, Secretary

TECHNOLOGY ADMINISTRATION

Phillip J. Bond, Under Secretary of Commerce for Technology NATIONAL INSTITUTE OF STANDARDS AND TECHNOLOGY

Hratch G. Semerjian, Acting Director 


\begin{abstract}
On May 3, 2004, NIST conducted a workshop to identify information needs for emergency responders during building emergencies. The workshop brought together emergency responders with the goals of sharing the vision of how the availability of building information can impact emergency response, and to gain from attendees guidance on what specific building information would be of greatest benefit to public safety officials, as well as how best to present it, and with what security measures. Prior to the workshop, NIST prepared a draft white paper detailing information needs of first responders at different times for different emergencies. During the workshop, the draft white paper served as a starting point for discussion with fire, police, and emergency medical responders. Based on workshop input, the white paper was both confirmed and extended. The revised paper is incorporated into this report.
\end{abstract}

Key Words: first responders, emergency responders, emergency response, emergency preparedness, building information, fire alarm system, fire detection, homeland security. 


\section{Table of Contents}

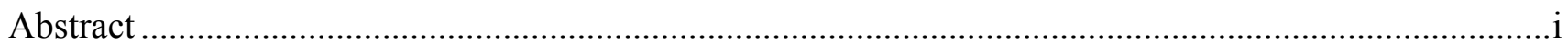

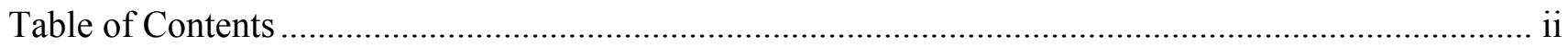

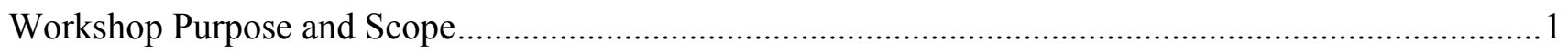

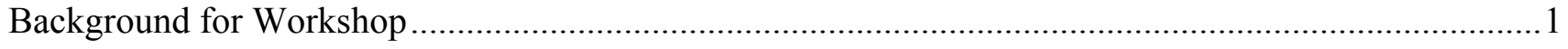

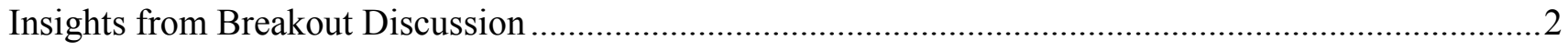

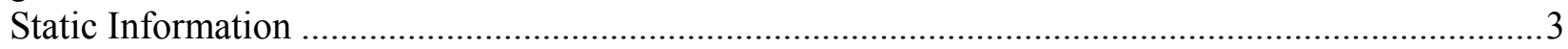

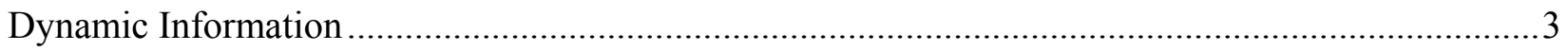

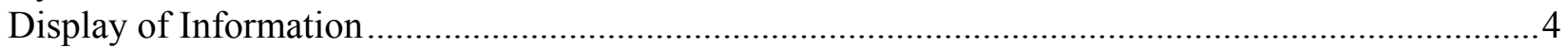

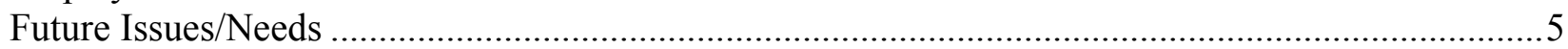

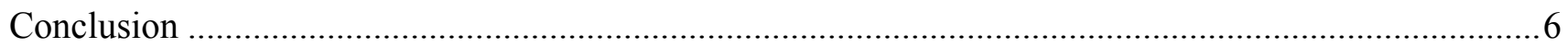

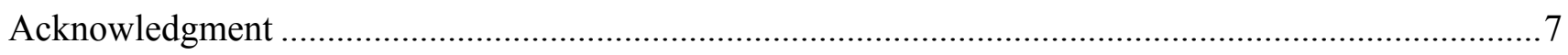

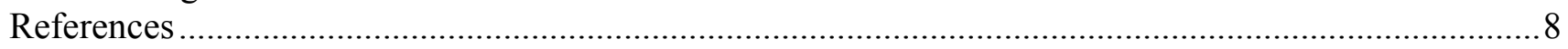

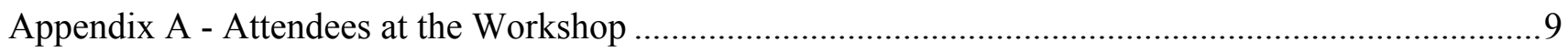

Appendix B - Agenda for the Workshop …………………………………………………………... 10

Appendix C - White Paper on Building Tactical Information for Public Safety Officials ......................11

Appendix D - Summary of speaker presentations ...........................................................................16

Ms. Kathleen Higgins: "Perspective of the NIST Office of Law Enforcement" ...............................16

Chief Ronny Coleman: "Future Information Needs for the Fire Service"..........................................17

Col. Joel Leson: "Interoperability and Standardization for First Responders"....................................22

Mr. Don Hewitt: "A Responder Knowledge Base for Police and Fire".............................................2

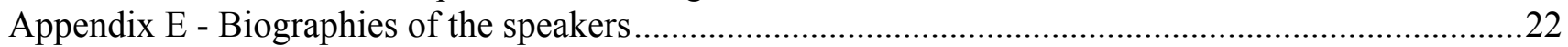

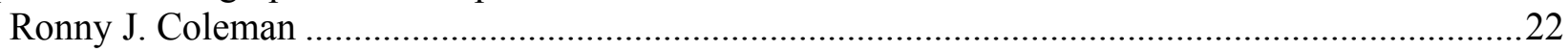

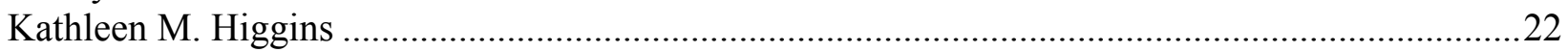

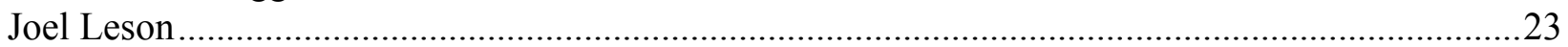

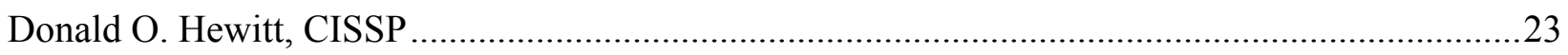

Appendix F - An Example Scenario Using an Incident Command Tactical System................................25 


\section{Workshop Purpose and Scope}

On May 3, 2004, NIST conducted a workshop on information needs for first responders. This workshop was organized as part of a Department of Justice, Office of Community Oriented Policing Services (COPS) funded project entitled, "Building Tactical Information System for Public Safety Officials". The purpose of this workshop was to meet with the community of first responders who are responsible for public safety with the focus on use of data contained in building systems. The main issue was identifying what building information would be of benefit to emergency responders at different stages of response to a building emergency and how it should be conveyed. The workshop included representatives from the police, fire, medical, building technology, government, and security communities. A list of attendees is provided in Appendix A, and the workshop agenda is given in Appendix B.

To set the stage for the workshop, NIST prepared a draft white paper on the issues of specific building information needed by emergency services. The information contained in the draft white paper was based on material from NFPA 1620 [1], pre-fire plan information from several sources compiled and supplied by Former California State Fire Marshall Ronny Coleman, Essentials of Fire Fighting, $4^{\text {th }}$ edition [2], several fire department websites, and discussions with Montgomery County Fire Captain Bob Vettori, Prince Georges County emergency medical technician John Demarest, fire protection engineer Erica Kuligowski and Fire Chief Don Oliver of Wilson, NC, Fire Department. Information was also used from a meeting of chief officers of fire and police to discuss the need and potential use of building information in emergency response, held in July of 2003 at NIST.

The approach of this workshop was to bring together speakers from different public safety organizations (fire, police, building technology, government, and security/terrorism) and to have attendees hear different perspectives on the information needs of different emergency responders, as well as to develop a vision for how information could aid in responding to building emergencies. The draft white paper was used as a starting point with the participants confirming, adding to, or modifying the information contained in the white paper. Issues and concerns associated with the presentation, security and use of building information were also discussed. As a result of the workshop activities, the draft white paper was updated. The updated version is included in Appendix C.

\section{Background for Workshop}

Many large buildings have building automation systems that manage the environment, security, fire, energy, elevators, etc. These systems process and store a large amount of data that is potentially useful to emergency responders: building maps and sensor data such as fire sensors, gas, temperatures, ventilation, door and elevator access, occupancy, lights, and cameras. There is significant work required to define what types of data are most useful to emergency responders at what time, and how to represent, transport, and present this data. Significant effort is needed to integrate dynamic (real-time) data that defines the status of the building to give emergency responders power to see what is happening in order to respond to an incident quickly and safely.

Critical building information needs to be sent to and displayed on a wide variety of display devices, from high-resolution screens at dispatch centers, wireless devices for notebook computers in fire apparatus/ police cars, and handheld devices. In order to assure interoperability of the information (or data) transmissions, requirements for the data and presentation formats must be defined as well. 
In the building industry, there is ongoing work to address building controls interoperability between different manufacturers, including the work on the BACnet [3] standard at NIST, and more recently work to provide building data to those outside the building. In the case of an emergency event, fire, police, and other emergency personnel arrive at a building and are faced with the need to quickly appraise the situation, find occupants, locate problems, determine the best way of dealing with the emergency, deploy resources, and then update tactical information as the event progresses.

Since the September 11, 2001 attacks on the World Trade Center and the Pentagon, there has been a focused effort to improve prevention, preparedness, response, recovery, mitigation, and coordination processes across the country. However, a comprehensive approach to providing building tactical information to building incident responders, applicable at all jurisdictional levels and across functional disciplines, would further improve the effectiveness of emergency response providers and incident management organizations across a full spectrum of potential building incidents and hazard scenarios. Such an approach would aid in coordination and cooperation between public and private entities in a variety of domestic incident management activities.

\section{Insights from Breakout Discussion}

The workshop schedule (see agenda in Appendix B) was broken into two primary activities: presentations and working group discussion. The purpose of the morning presentations was to have several experts to provide their perspectives on the potential impact of having accurate and reliable information from building systems for tactical decision aids. Summaries of the morning presentations have been included in Appendix D. Speaker biographies are presented in Appendix E.

After lunch, the participants were organized into two working groups to further discuss information needs with the objective of adding or subtracting and prioritizing the information in the draft white paper. The two groups worked in parallel and then assembled again to brainstorm and attempt to arrive at a final list of information. Points that were emphasized during the workshop were that the display of information must be kept simple and that the electronic display systems must be robust. The draft white paper that was distributed to workshop attendees and used as the guide for discussion was updated based on the input received during the discussion time and at a subsequent NFPA meeting in May 2004. This updated document is presented in Appendix C.

In attempting to summarize what was learned at the workshop, it is helpful to classify the various topics discussed following the lines of the white paper:

1. Static information

2. Dynamic information

3. Display of information

4. Future issues/needs 


\section{Static Information}

Static Information is defined as that building information that is available before an incident. Typically the fire service will survey large and/or special buildings to collect information that would be useful in the event of a fire. Likewise, a building automation system may contain useful information such as floor plans, sensor locations, and ventilation system schematics. This is all "static" data and potentially of use in a building emergency. The white paper in Appendix C contains a more complete list of static information that includes items identified prior to the workshop.

Some of the static information issues discussed included:

- Where are the ingress/egress locations in the building-location of access points such as doorways, stairways and elevators?

- What systems are available to mitigate the incident (e.g., which standpipe is best)?

- Where are the hazards and obstructions in the building?

- What generators power what systems; what can be safely turned off?

- Where are the nearby hazards outside the building that may be affected by the incident, e.g., building to building fire spread?

- Pictures should be included of sides of the building (labeled in fire service notation $a, b, c, d$ ).

- Simplified drawings should be utilized instead of complete building drawings.

- Include utilities, lock boxes, standpipes, door locations, zone boundaries, hazardous materials, fire walls, roof access, stairwells, elevators, camera locations, security and fire control room(s), and water sources.

\section{Dynamic Information}

Dynamic information is that set of information that comes from real-time status of building system controllers and sensors, including fire alarms, security sensors, mechanical system status, elevator location, lighting system activation, occupancy sensors, etc. Dynamic information includes both direct sensor readings, as given by individual building subsystem controllers, and the output of decision support tools that analyze sensor data. An example of a fire decision support tool is one that would use the fire system sensors along with knowledge of the building geometry to produce fire size, location, and fire growth rate estimates. Another example is a security support tool that estimates occupant location based on occupancy sensor and lighting system input.

Some of the dynamic information issues discussed included:

- Where is the incident located within the building?

- How big are the fires and what are their durations?

- Where is the smoke located in the building?

- Smoke and heat sensors in stairwells would be beneficial, especially for egress.

- Are building systems operating to mitigate the fire or other incident?

- Are people still inside and at risk?

- How many occupants are handicapped or have limited mobility and where are they located?

- Where are toxic chemicals located that could be involved?

- What is the change in structural integrity of the building during the incident?

- What evacuation routes are available or blocked?

- Which stairwell is best? 
- Where are triage locations?

- Security (access control) time history is of particular interest to law enforcement.

- What is the mechanical system status for water, power, and ventilation?

- Is the sprinkler system activated?

- Are the air handling units shut down?

- Is the power shut down?

- For building subsystem status, what systems are still operating, i.e., HVAC, smoke evacuation, elevators?

- What systems have stopped reporting?

- Are sensor readings reliable or is system status uncertain?

- Positive diagnostics and fault detection are needed.

- Exposure of nearby buildings from any threat such as fire, hazardous materials, bomb blast radius and chemical/radiation profiles for buildings.

- Guidance on where to stage (outside for vehicles, inside for civilians).

- Predictions and status of weather conditions at the site using sensors on the outside of buildings and/or local weather stations.

- Projection of where water or foam runoff will occur.

- Type and duration of training required to use intelligent systems.

\section{Display of Information}

While display of information was a planned topic of the workshop, information presentation became an issue of considerable discussion.

1. The idea of a 3D display was discussed in reference to making clear the relationship among things. At the same time it was repeated often that displays must be simple. So, in order to be useful, they must be both rich in information, but presented in a simple, uncluttered and (relatively) easy to use interface. In concert with this, it is important to use only a few icons, at least on the general purpose screens. For example:

- Drop of blood for caution on body fluids

- Skull and crossbones for hazardous materials

- Person icon for life safety issues (occupants or rescue workers)

- Fire icon for fire

- Pistol or rifle icon for shots fired or known shooter

- Bomb icon for reported bomb

2. It was noted that information distribution is uneven and that it needs to occur via multiple paths: book, mobile data computer or simply building familiarization. Audio could be effectively used to augment a visual information presentation. For the fire service, it allows everyone to be in the loop, not just the commander, and will improve understanding which improves response. On the law enforcement side, since a squad car usually has only a driver, audio may be the only way to get information enroute.

3. Attendees didn't think text-only displays would work (although this will depend on application). They liked graphics - maybe 3D for pipes and stairwells and 2D for incident location (floor plans). 


\section{Future Issues/Needs}

Some issues raised in the discussion were not information needs based but are included here and may be addressed in the future:

1. The issue of improved dispatch that would be actively involved in information sharing between services was raised multiple times. The general conclusion was that dispatch service needs to be improved, including standardizing on communication phrases, and needs to receive additional and more comprehensive training.

2. The issue was raised of implementing control capabilities into an information system interface, for example, to direct personnel placement or evacuation. This would effectively automate some of incident command and lead to less voice communication. Attendees were hesitant about this, considering that they felt the need for person-to-person communication which was judged particularly important in making any decision that involved multiple services. Clear command authority would somehow have to be implemented in the computer interface.

3. First responder control of building systems, via the information system interface, was discussed. This might include shutting off air handling units, unlocking doors, directing closed circuit TV cameras, turning off power and water. Participants thought this would be good, but again were concerned with command authority issues. The suggestion was made that personnel closest to an incident requiring control should have priority in making decisions to control the incident. For example, a fire fighter in an elevator could override the instructions from the building security control panel; except that there were noted occasions where the reverse is true.

4. Updating "static" information in a timely manner is important. Somehow, there needs to be a link with the building permit process, and feedback through inspections. Building use status changes frequently and changes are not always propagated through the municipal database. The suggestion was made to somehow have building owners responsible for maintaining current building layout, use, and history.

5. The point was raised of the possibility of linking a traffic control system to facilitate emergency access. Is it possible to automatically manage traffic flow to bypass the event?

6. Personal information protection (i.e., compliance with the Health Insurance Portability and Accountability Act of 1996 (HIPAA)) still must be considered:

- Limit personal medical information to authorized individuals and

- Limit access to criminal history records for specific individual for crimes.

7. There is information which might not be shared, e.g., classified movement of munitions or nuclear material through an area for which state and local officials may not be cleared. What classified information might be included in the information system, and to whom would it be made available? 


\section{Conclusion}

The major outcome of the workshop was the identification of information needs for first responders which were broken down into information needs while enroute and on arrival to the incident scene. The list of information needs contained in the draft white paper were verified and added to by the workshop participants.

Outcomes of the workshop included:

- Identification of the building information needed by emergency responders prior to reaching the scene and on the scene (Appendix C);

- Recognizing that the methods used to present this information must be kept simple and should include both audio and visual components;

- Available information enroute must be carefully selected as fire incident commanders typically have very little time to look at it prior to arrival on the scene;

- Use of audio can be extremely useful enroute for those emergency responders unable to view visual information (e.g. drivers, team members in a cab) about the progressing emergency situation;

- Needs for police and EMS were discussed and included in Appendix C, but additional input is needed due to the limited number of representatives from these areas.

There was general agreement that the types of information that could be sent to the incident commander would provide more safety and better informed command decisions. There was also concern that too much information would lead to information overload. There was some discussion about presenting building information in 3D formats. Short text messages were also suggested as useful in addition to graphic display icons. See Appendix F for a suggested example scenario contributed by one of the participants.

The next step for the project is to use the results of this workshop to produce a guide to minimum information needs for use by the building systems and monitoring industries; consensus standards organizations; and others concerned with first responder safety and effectiveness. Future steps are to demonstrate the technology, develop the basic understanding of the decision support systems and other building technology to achieve reliable outcomes, and promote the acceptance and codification of the proposed standards.

The work reported here represents one part of a project designed to pave the way to deliver building information to first responders. Other issues that are currently under development include the development and population of a building information model, the development of standards for publish/subscribe servers, messaging standards for the transfer of building information, security issues associated with the information transfer, the construction of first responder information displays, and the development of decision support systems. 


\section{Acknowledgment}

This workshop was sponsored by the Department of Justice Community Oriented Policing Service (COPS) via the NIST Office of Law Enforcement Standards (OLES) to advance the development of the Building Tactical Information System for Public Safety Officials project. 


\section{References}

1. "NFPA 1620, National Fire Alarm Code, 2003 Edition" (2002).

2. Richard Hall, Barbara Adams, Essentials of Fire Fighting, $4^{\text {th }}$ edition, International Fire Service Training Association, June 1998.

3. "ANSI/ASHRAE Standard 135-2004 BACnet - A Data Communication Protocol for Building Automation and Control Networks" (2004). 


\title{
Appendix A - Attendees at the Workshop
}

\author{
Name \\ Affiliation \\ Captain Danny Baker \\ Chief Richie Bowers \\ Mr. J. Robert Boyer \\ Mr. Steven Bushby \\ Chief Ronny Coleman \\ Dr. William Davis \\ Dr. David Evans \\ Chief Jay Farr \\ Mr. Edwin Freeborn \\ Lieutenant Randy Godwin \\ Lieutenant Chris Granger \\ Mr. Don Hewitt \\ Ms. Kathleen Higgins \\ Dr. David Holmberg \\ Mr. Michael Johnson \\ Dr. Walter Jones \\ Mr. James Kauffman \\ Dr. George Kelly \\ Mr. Clyde Lansing \\ Col. Joel Leson \\ Lieutenant Dallas Lipp \\ Dr. Kent Reed \\ Captain Robert Vettori \\ Captain Gary Wedemeyer \\ Lieutenant Steve Yannarel \\ NIST Fire Department \\ Montgomery County Fire and Rescue (MD) \\ Edwards Systems Technology \\ NIST Building and Fire Research Laboratory \\ Fireforceone \\ NIST Building and Fire Research Laboratory \\ NIST Building and Fire Research Laboratory \\ Arlington County Police (VA) \\ L3-Com, NLECTC-NE \\ Operations Officer, Wilson Fire Department (NC) \\ Prince William County Department of Fire and Rescue (VA) \\ Terrorism Research Center \\ NIST Office of Law Enforcement Standards \\ NIST Building and Fire Research Laboratory \\ Medic, Charlottesville Fire Department (VA) \\ NIST Building and Fire Research Laboratory \\ Ascentry Technologies, Inc \\ NIST Building and Fire Research Laboratory \\ Fresno City Fire Department (CA) \\ International Association of Chiefs of Police \\ Montgomery County Fire and Rescue (MD) \\ NIST Building and Fire Research Laboratory \\ NIST Building and Fire Research Laboratory \\ Fresno City Fire Department (CA) \\ Prince William County Department of Fire and Rescue (VA)
}




\section{Appendix B - Agenda for the Workshop}

\section{BWI Marriott, Baltimore, MD May 3, 2004, 8:30 AM to 4:00 PM}

This workshop is to obtain guidance on the type of building information, pre-plan as well as real-time system, needed for emergency response to incidents in buildings.

8:30 Welcome and Overview of the Workshop - Walter Jones

8:40 Self Introductions

9:00 Opening Remarks, Kathleen Higgins, NIST Office of Law Enforcement

9:15 Overview of the NIST project - Dave Evans

9:30 Trends in Integrating Building Automation Technology - Steve Bushby

9:45 Break

10:00 Vision of Information Technology for the Fire Service - Ronny Coleman, National Association of State Fire Marshals

10:30 Interoperability and Standardization for First Responders - Joel Leson International Association of Chiefs of Police

11:00 A "Responder Knowledge Base" for Police and Fire - Don Hewitt Terrorism Research Center, Inc.

11:30 Lunch

12:30 Purpose of the Workshop and guidelines for the working sessions - Walter Jones

12:45 Review of the discussion paper - William Davis

1:00 Working sessions

Session 1 coordinators: Dave Evans, Steve Bushby

Session 2 coordinators: Kent Reed, William Davis

3:00 Break

3:15 Convene for discussion of results

4:00 Adjourn 


\section{Appendix C - White Paper on Building Tactical Information for Public Safety Officials}

\section{Introduction}

Response to a building incident typically commences with a 911 call. Dispatch provides first responders with the type and location of the incident and determines order of dispatch. A map of the running route will be carried in the emergency vehicles along with building keys and a Knox Box key (a Knox Box is a fire service lock box that is attached to a building and contains the building keys) although not every building will have a Knox Box or keys. When keys are available, they open outside doors, utility rooms and mechanical rooms.

For the fire service, hydrant locations may be indicated on the route map, while the extent of the building information on the map depends on the type and use of the building. For commercial buildings or apartment houses, the map may include an outline of the building and the location of the standpipe/sprinkler connection and door/garage entrances. For newer buildings, the location of the annunciator panel and fire control room is sometimes available. Additional information about the structure may be available in binders carried in the responding apparatus. These preplans may contain interior floor plans, locations of stairwell risers, the location of utility shutoffs, known hazards, etc. Its detail will depend on the person that did the work.

With the development of small, rugged portable computers and compact electronic storage media, the information available to a first responder about a building or other incident can be expanded and made more accessible. Advances in telecommunications have opened up the possibility of supplying first responders with real-time information about the building and incident prior to arrival. Fire departments are moving toward using electronic pre-emergency plans (e-plans) for buildings that can be accessed from computer terminals in the apparatus.

Recent work at NIST has demonstrated the possibility of using building sensors and a decision support system to send information about a developing building fire to first responders prior to their arrival at the building. When added to the information that pre-plans can contain (see NFPA 1620), the amount of building information that can be made available to emergency responders is overwhelming. This paper is designed to start a dialogue that should result in the development of a set of minimum standards for building information provided to first responders while enroute and on the scene of building incidents. The goal of these standards is to provide responders with static (pre-plan) and dynamic (real-time) building information in a format that is readily understandable and is universally accepted such that the use of the information becomes seamless.

An incident can be broken down in time to three general periods. The first period is the time from dispatch until arrival at the incident; typically about five minutes. The second period is the time from arrival until the extent of the incident and method of attack has been determined, and the last period is the mitigation of the incident. The amount of information needed during each of these periods will depend on the type of incident. The key is to look for commonalities in information across incident types and develop information groups that can be readily displayed on a computer screen.

The next sections explore possible minimum information sets for several different incidents. The information contained in these sections prior to the workshop was based on material from NFPA 1620; pre-fire plan information from several sources compiled and supplied by Santa Rosa, CA, Fire Chief Ronny Coleman; Essentials of Fire Fighting, $4^{\text {th }}$ edition; International Fire Service Training Association; several fire department websites; and discussions with Montgomery County Fire Captain Bob Vettori, Prince Georges County EMS responder John Demarest, fire protection engineer Erica Kuligowski and Fire Chief Don Oliver of Wilson North Carolina Fire Department. Information was also used from the workshop on first responders held in July of 2003 at NIST. The following information has now been updated to include input received during the May, 2004 workshop, as well as some follow-on information received from attendees of the NFPA May, 2004, meeting in Salt Lake City. 


\section{A building fire, the first five minutes}

The "first due" responder typically has five minutes between time of dispatch and arrival at the incident. The officer in charge must make sure that his team is seated and belted in the apparatus, dressed in turn-out gear, and that all the doors are closed. The officer must then check with the driver to make sure that the route to the incident is known and then uses the route map to verify that the route is correct.

At this point, the officer can start to process additional information about the incident. Due to the difficulty of reading computer screens or hard copy when the apparatus is in motion, the information display must be simple which limits the quantity of information that can be displayed. The information that may be displayed comes in two categories, static or time independent information and dynamic or real-time information.

\section{$\underline{\text { A building fire }- \text { en route }- \text { the first five minutes }}$}

- Building occupancy (abandoned, vacant, number of young children, high occupancy, number of elderly, numbers of occupants should be based on time of day).

- Building condition (let burn, unsafe to enter, dangerous roof, sprinklered and other suppression systems)

- Building type (single family, commercial, gas storage, school).

- Building style (one story, two story, $\mathrm{n}$ story, auditorium, sublevels, etc) include square feet.

- Building construction (type I, II, III, IV or V; fire resistive, noncombustible or limited combustible, ordinary, heavy timber, or wood frame - see reference 2 ).

- Roof construction (light weight metal or wood trusses).

- Hazardous materials (Unusual hazards) (above ground propane tank, gas lines, chemicals, etc)

- Location of fire hydrants on map with building outline. Nonstandard thread sizes should be noted with the hydrant.

- Location of fire department hookups for sprinkler system/standpipes.

- Other sources of water nearby.

- Location of staging areas and entrances and exits to building.

- History of location in case fire stages before police arrive.

- Routing information for emergency equipment to reach the building in case of construction.

\section{The dynamic and calculated information available to the first responder}

- Confidence in the incident being real (based on number of sensors in alarm and/or calculated fire size)

- Approximate location of fire within building.

- Fire size and duration.

- Estimated water flow in gallons/minute or foam based on fire size

- Assessment of the local hydrants capability of supplying this water.

- Sprinklers are flowing/no sprinklers or other working systems.

- Fire growth (fast, medium, or slow).

- CBR (chemical, biological, radiation) sensors present and in alarm.

- Police on the scene.

- Presence of occupants in building

- Stairwell smoke/heat conditions for positioning.

- Standpipes to use to get to the fire.

- Exposures.

Other units responding to the scene should receive the same type of information even though it may take them an additional five to ten minutes to reach the incident. The fraction of this information that can be supplied will 
depend on the building type and age with new, large commercial buildings having the infrastructure to supply most of the points on the list.

\section{On the Scene}

Once the first apparatus has arrived, the incident commander will require additional information. For house fires and other small buildings, a visual inspection from the outside and information supplied by occupants would be a first priority. For large buildings, the fire may not be visible from the outside and a visual check may not be a first step. Typically, large buildings have twenty-four hour security or desk people that may provide information on where the incident is located within the building.

Electronic data that would be useful at this time would include a building floor plan and a plot plan of the area. The floor plan (static data) would include layers/overlays that would allow the incident commander to locate:

- Key box.

- Doors, windows (with types and which can be used for egress), stairwell risers, fire walls (with ratings and area separation), roof access, fire sensors.

- Security sensors, closed circuit TV cameras, occupancy sensors, security control room.

- Fire alarm panel and remote annunciator panels.

- Utility shutoff.

- Building generator (with indication of what it powers)

- Building system controls (HVAC, smoke control, others), areas covered, special operating systems, and which ones should and should not be used by the responders.

- Persons with special needs.

- Areas of refuge.

- Evacuation quality elevators, floors served, and location of elevator overrides and how to control.

- Convenience stairs/evacuation stairs.

- Areas (zone boundaries) protected by sprinklers or other devices.

- Hazardous materials (type indicated)

- Potential building hazards that may require decontamination.

- Vertical openings.

- Extremely valuable materials.

- Contact number for building engineer.

Dynamic and calculated data that would be useful and could be a series of overlays on the floor plan include the following:

- Location of fire detectors in alarm.

- Location of CBR sensors in alarm.

- Location and size of fire/fires.

- Duration of the fire/fires.

- Location and condition of smoke.

- Presence of smoke in elevator shafts or stairwells.

- Identification of activation of sprinklers or other devices.

- Location of elevators used during incident.

- Location of people in need of rescue (911 calls or visual sightings).

- Warnings of structural collapse based on material type, fire location, fire size and duration.

- Location of operational elevators.

- Alarm, occupant, and system histories of building. 
The plot plan (outside building) would be resizable and contain the following information:

- Building location with street designations.

- Location of fire fighting obstacles such as street widths, overhead clearance and elevations.

- Location of underground pipelines and other utilities.

- Name and phone numbers of building owners and managers.

- Name and phone numbers of utility contact people.

- Location of police line necessary to isolate the incident.

- Indicated runoff or water table problems.

- Helicopter landing areas.

- Evacuation routes.

- Bomb blast radii for buildings.

- Chemical/radiation staging.

Dynamic data that could be displayed on an overlay of the plot plan would include:

- Location of responding units (fire, police, and EMS).

- Location of units responding but not yet on scene.

- Hospital availability.

- Helicopter availability.

- Hazmat response.

- Location of police line necessary to isolate the incident.

- Location of triage or evacuation area.

- Suggested hazard perimeter.

- Local weather conditions and predicted spread directions.

- Wind direction and velocity.

Additional data that may be needed concerning the incident include a long list of contact numbers for public safety or relief agencies.

\section{Medical Emergency}

A medical emergency within a building can require a subset of the information needed for a building fire. For large structures, the location of the victim and how to get to him/her is of primary importance and a simple floor plan becomes very useful. On dispatch, a route map and a simple plot map showing the outlines of buildings and adjacent streets would be useful. Upon arrival at the building, a simple floor plan containing the following static and dynamic information would be required.

The e-plan floor plan display should include the following static information:

- Doors and stairwell risers.

- Elevators with elevator cars designated for ambulance stretchers.

- Building hazards that may require patient decontamination.

Dynamic data that would be useful include:

- Nature of medical emergency and estimate of need for patient transportation.

- Location of patient.

- Quickest route in building to location.

- Victim data including age, size, sex, allergies and pre-existing medical problems.

- Police on scene. 
- Hospital availability.

- Helicopter availability.

\section{Police Action}

Building information that would be useful for an incident involving a break-in or other criminal incident would require a building floor plan with different sets of sensor data than would be used for a fire. Static data that should be included consist of a building floor plan and plot plan and a route map.

The building floor plan should include the location of:

- Key Box.

- Doors, windows and stairwell risers.

- Security alarm panel and remote annunciator panels.

- Utility shutoff.

- Hazardous materials (and types).

- Motion detectors.

- Surveillance cameras.

- Security office.

- Security zones and door access point locations with type of security (key, card reader, biometric device, RFID reader)

- Telephones and corresponding phone numbers.

The plot plan should include:

- Building location with street designations.

- Building occupancy (abandoned, vacant, young children, high occupancy, elderly).

- Building type (single family, commercial, gas storage, school, etc)

- Building style (one story, $\mathrm{n}$ story, $\mathrm{n}$ story with basement, auditorium, etc).

- Name and phone numbers of building owners and managers.

- Name and phone numbers of utility contact people.

Dynamic information from sensors that would be involved with security would include:

- Door access history, location and progress on intrusion.

- What security devices were operated (tripped) and their location and time of operation.

- Lighting and elevator use history.

- Location of activated motion sensors and other security sensors.

- Surveillance cameras.

- Confidence in the incident being real.

As police respond to a building alarm, bringing up this information electronically either within the responding patrol car or at the police station would provide the responders with a tactical advantage compared with what is now available.

\section{Summary}

This list of information represents a first cut for electronic information available at an incident. In particular, needs for police and EMS were discussed and are included here but additional input is needed due to the limited number of representatives from these areas. While additions and subtractions to this list are expected over the next months, a next step is to decide how to order the information by electronic screens and standardize the symbols 
used on the displays. An excellent starting point is NFPA 170, Standard for Fire Safety Symbols, and NFPA 72 annex, National Fire Alarm Code. A subset of these symbols should represent a starting point for the e-plan standard. There are several companies developing GIS based software that is being used for preplanning by fire and other public officials and the good ideas in their products should be incorporated in the standard.

Discussion of the display of information led to the following conclusions. The methods used to present this information must be kept simple and can include both audio and visual presentations. Audio can be very beneficial in communicating to a first responder who must watch the road, or to others in a vehicle who cannot see a visual display. Specific phrases used in audio messages should be standardized. The use of colors on displays needs to be explored as an aid in recognition of information. There was some discussion about presenting building information in 2D or 3D formats, with participants agreeing that need for 3D information was limited. The use of icons in some instances was also suggested but short text messages could also be effective. A set of symbols is useful for the video display and would include:

- Drop of blood for a medical hazard

- Skull and crossbones for hazardous materials

- Life safety for a person

- Fire symbol for a fire

- Gun symbol for shots fired

- Bomb symbol for a bomb.

Finally, available information enroute must be carefully selected as the incident commanders typically have very little time to look at it prior to arrival on the scene. There was general agreement that the types of information that should be sent to an incident commander would provide more safety and better informed command decisions. There was also concern that too much information would lead to information overload.

\section{Appendix D - Summary of speaker presentations}

This section presents a summary of the morning presentations. The purpose of the presentations was to have experts provide their perspectives on the potential impact of having accurate and reliable information from building systems for tactical decision aids. Speaker biographies are presented in Appendix E. The presenters were as follows:

Kathleen Higgins: Director, NIST Office of Law Enforcement Standards

Ronny Coleman: Fire Chief, Santa Rosa, CA, Fire Department and former CA State Fire Marshall

Joel Leson: $\quad$ Special Assistant to the Executive Director \& Chief of Staff /Staff Liaison to the Homeland Security Committee, International Association of Chiefs of Police

Don Hewitt: $\quad$ Program Manager, Responder Knowledge Base, Terrorism Research Center, Inc.

\section{Ms. Kathleen Higgins: "Perspective of the NIST Office of Law Enforcement"}

The NIST Office of Law Enforcement Standards (OLES) came about with the recognition in the 1960s of the need for equipment standards and information sharing. The National Institute of Justice came to NIST and cooperatively set up OLES, which has since addressed many issues of interest to the law enforcement community. 
After 9/11 there was a significant expansion and refocusing on homeland security issues. This was true not only at OLES but also in every local jurisdiction. And while interoperability issues have been known and potential technology to address the needs available, post 9/11 has seen new determination at the federal and state levels as well as at the local levels to make interoperability a reality. Post $9 / 11$ has seen the concentrated efforts of the federal government as demonstrated by the establishment of Department of Homeland Security (DHS) and steady evolution of programs within DHS to address needs of the emergency response community.

The DHS mission focuses on (1) preventing terror attacks and (2) responding to terror attacks. Part of response is having necessary equipment, and a second part is having information. The focus of the current workshop is getting building information out to the emergency responder. The goals are collaboration and sharing about the future of emergency response. This work goes beyond the traditional law enforcement focus of OLES and beyond the terror focus of DHS, because it is useful for any building emergency in the everyday work of emergency responders.

\section{Chief Ronny Coleman: "Future Information Needs for the Fire Service"}

Chief Coleman began his talk by describing the contributions of two men in order to provide a historical basis for his talk.

- Sir Eyre Massey Shaw, London Fire Brigade, who authored "A Complete Manual of the Organization, Machinery, Discipline, and General Working of the Fire Brigade of London" in 1876. A quote from this manual, "If you wish to control a problem, you must know more about the problem than anyone else and if you need to know more about the problem, you must coin a terminology, a lexicon, that allows you to understand it and not use imperial rhetoric." So, don't just be random about your collection of information, have a systems approach to it. In 1876, the London Fire Brigade was already developing fire pre-plans for buildings.

- Lloyd Layman authored "Fire Fighting Tactics" in 1953 (first published in 1940 under the title: "Fundamentals of Fire Fighting Tactics") and developed the concept of "size-up." Size-up encompasses facts, probabilities, possibilities, plan of action, etc. for an incident. "If you are going to rush into an emergency, you better have your information together."

“Today (2004) I would characterize the Fire Service as having one foot firmly planted in the 1870's and the other foot firmly planted in the 1950's and grasping to catch up with technology."

The first issue the Chief discussed was Risk Assessment. It is a limitation and potential liability for fire departments that very few communities know about Risk Assessment, and there is a great need to have better knowledge of Risk Assessment. He is working to develop RAVE, Risk Hazard and Value Evaluation, which is a computer-based methodology for risk assessment of buildings. It addresses the questions of:

- What is in the building?

- What can hurt you in the building?

- What do you need to know about the building?

Without a model to understand how everything fits together, there is a gap between the fire community and the technology community. The Chief gave his perspective in the following chart which provides an overview of how fire departments across the country are using data and technology and how the use of technology evolves. 


\section{Fire Department Use of Data and Technology}

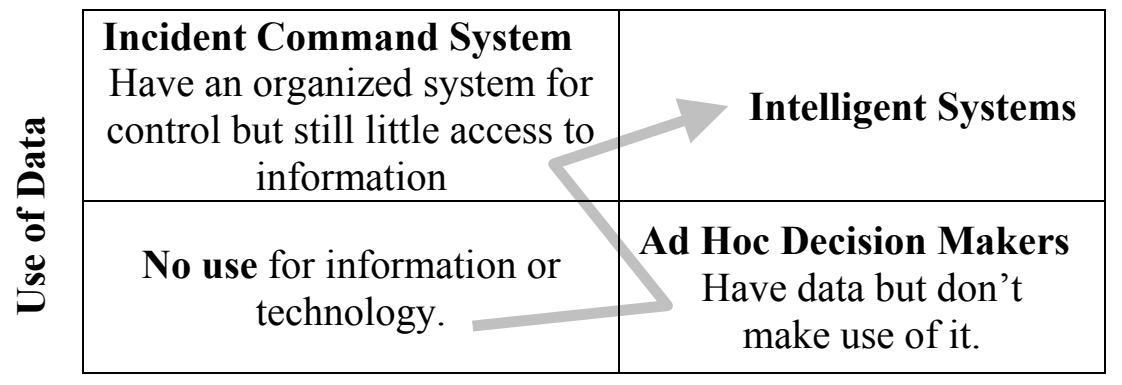

DATA, How Much You Know

Fire departments typically follow the path of the arrow in their use of data and technology from the No Use phase, to the Ad Hoc decision makers who have no systematic use of the data they have collected, to the typical large department today that has an ICS but still doesn't get all their data (nor potentially useful data from other sources) to the fire ground. A few fire departments are currently evolving to the intelligent systems phase.

Intelligent systems are the end goal, and those systems need to supply information at three levels: to the fire fighter, the incident commander, and the department. The first fire fighters on the scene need information fast to make correct decisions. An example showing the benefit of building information can be seen in evaluating the fire service requirement of " 2 in -2 out" for a building fire. The current situation for fire fighters arriving on scene is that they have little information with which to make decisions and can only enter the building if there is a backup crew for rescue. If information about the condition in the building were available, then in cases without IDLH (immediately dangerous to life or health) intervention could occur without the need for a backup crew.

The graph below shows the development of a typical fire in a building. Most current technology introduced to the fire service recently has focused on getting the fire truck to the scene as quickly as possible (CAD, GIS, $800 \mathrm{MHz}$ radio). The time between alarm activation and fire truck arrival is typically four or five minutes, and this is where the big money is spent, rather than taking information available before the fire and making that available to the incident commander.

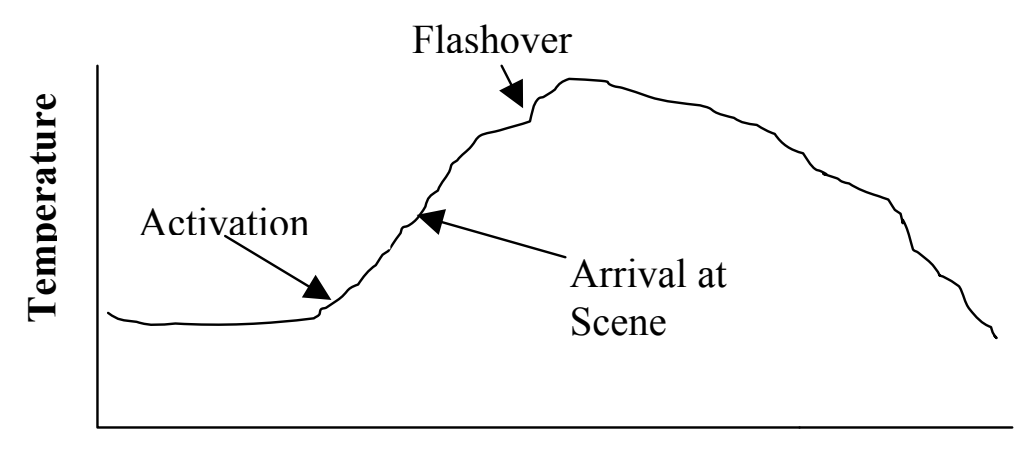

Time 
The fire service is reluctant to adopt technology until its $100 \%$ worthy of their acceptance. They will not accept partial solutions and don't like unreliable solutions. The reason is the consequence of failure at the scene of the fire. This issue needs to be addressed.

The Chief is part of a group "Mapping the Future of Fire." Most fire departments have file cabinets full of information that is unavailable at the scene of the emergency. Fire agencies use defensive record keeping which accounts for the large amount of collected data. The challenge is to make use of this data at the fire scene. More and more metropolitan fire departments are going to use their mobile data terminals to bring these data to the fire ground although there are technical issues. The project is answering the question of "is it possible to use GIS and Fire Department Data in the planning process to make a better fire ground performance?" The key is that the data has to be used prior to activation or applied between activation and arrival to be effective.

An example of the difference between waiting for something to happen and using data before activation can be found in a study conducted by Chief Oliver of the Wilson, NC, Fire Department. Using a combination of data on hydrant water flow, required water flow, and GIS it was determined that several locations in Wilson had insufficient water flow. This deficiency was corrected which prevented potential fire ground problems.

As fire departments develop the capability to use data on the fire ground, they also need to identify reliable sources for data. The Chief noted several outside sources of data available to fire departments:

- The Insurance Services Offices of the US (ISO) has an extensive commercial building database.

- City building department and GIS department

- Arson Bureau and hazardous material records

Obtaining building plans and other fire ground information requires the fire department to work with other city agencies and organizations such as ISO.

In summary:

1. Fire service will not adopt a technology unless they have a chance to break it first. New technology must be taken to the firehouse level. You have to pilot test.

2. You can't wait until a product is "perfect" before you pilot test it.

3. You have to get the technology into the training environment before it begins to work.

There are three stages of technology in the fire service today:

1. It won't work!

2. It works and I can't afford it.

3. How did we ever get along without that before?

Some final thoughts on making it work:

- Anything that can be done to connect data systems with communication and activation systems will compress the time between activation and arrival and increase the efficiency and the effectiveness of the fire department.

- The fire service is ready, willing, but not quite capable of adopting technology. Most of the energy and effort is going into dispatch and radio systems and not into support systems for the incident commander. Need to get information to the IC level. And need to get it into the training system.

- Technology costs money. What is needed are applications that are affordable for a large number of entities to use on a real-time basis. Fire departments cannot be expected to supply the funding 
for new technology. The good news is that there is a growing interest in the private sector (e.g. Building Owners and Managers Association) in private-public partnerships to make the technology work.

- And last but not least, "Facts make a difference."

\section{Col. Joel Leson: "Interoperability and Standardization for First Responders"}

"It isn't just the fire service. Everything the chief (Chief Coleman) said is as true, in many instances, in the police service as it is in the fire service." The police service is no better off at implementing the technology. Of the 20,000 members of the International Association of Chiefs of Police (IACP), seventy percent are made up of departments of 25 or less. While the large departments can handle the new technology, the small departments have problems.

In a study of EMS, fire, and police needs ["Incident Command Technology Systems for Public Safety," report prepared for DOJ, NIJ Office of Science and Technology, by The Center for Technology Commercialization, Inc., August, 2002], the following list of first responder (fire and police) technology needs was given:

- An effective command and control system for managing critical incidents;

- Communications systems to allow all first responder disciplines and agencies to speak to each other;

- Coordination of resources;

- Safety systems including tracking and monitoring of personnel;

- Access to real-time, accurate information;

- Broad-based training and scenarios; and

- Access to a clearinghouse or database of available technology solutions to assist in managing critical incidents.

The implementation of these needs will only be successful if we can get it to the street and are willing to spend the necessary money. As Chief Coleman stressed, only a few communities have reached a level of expertise where they can use the technology properly or afford it.

What do we need to fix the problem? Money is the first step but it must be spent wisely. We must get into the threat assessment business in order to figure out where to direct the money. The second step is education. The IACP is preparing to use workshops to start the educational process. The goal is to get people to the point where use of technology is second nature. "We have to make sure that every young person that goes on a payroll is funded and trained." We need to develop a complete transparency in operations between fire, police, and EMS.

\section{Mr. Don Hewitt: "A Responder Knowledge Base for Police and Fire”}

Don presented an overview of the Responder Knowledge Base (RKB), a trusted knowledge base for emergency responders, online at www.rkb.mipt.org. Prior to the development of the RKB there was no reliable unbiased source of practical information about the performance of equipment needed for safe and effective response to emergencies. The RKB was developed as part of Project Responder, sponsored by the Oklahoma City National Memorial Institute for the Prevention of Terrorism (MIPT). Funding is also received from the Office for Domestic Preparedness, Department of Homeland Security. 
The mission of the RKB is "To provide Emergency Responders, purchasers, and planners with a trusted, integrated, on-line source of information on products, standards, certifications, grants, and other equipment-related information."

The RKB has been designed to provide Emergency Responders with a single source for integrated information on current equipment, including organizing information such as the InterAgency Board's Standardized Equipment List (SEL), the Authorized Equipment List (AEL) from the Office for Domestic Preparedness, and National Terrorism Response Objectives from Project Responder itself. By integrating this information in one location, responders, vendors, standards organizations, training facilities and grant making organizations will have a trusted first source to begin answering questions such as:

- What equipment is out there?

- Has it been certified?

- To what standard?

- What training is needed to use it?

- How do I pay for it?

- Whom can I talk to who has used it?

In operation, the Knowledge Base is based upon the concept of direct relationships, or "knowledge links" among various types of content items. These content types include the InterAgency Board Standardized Equipment List, the ODP Authorized Equipment List, Products, Standards, Certifications, Grants, Training, and Project Responder's National Terrorism Response Objectives. Registered professional responders also have the ability to contact other responders who have had operational experience with listed products, or volunteer to share their own experiences. 


\title{
Appendix E - Biographies of the speakers
}

\section{Invited Speakers}

\author{
Ronny J. Coleman
}

Ronny J. Coleman is a principal in Fire Force One, a company that provides a variety of fire protection services. Fire Force One operates a website to help support research of local fire agencies. He also serves as the President Emeritus of the Fire Education \& Training Network. He serves as a technical consultant to the International Code Council (ICC) on code issues and the Environmental Systems Research Institute (ESRI) related to GIS mapping. He formerly served as the California State Fire Marshal and retired as Chief Deputy Director, of the California Department of Forestry and Fire Protection. Previously he was Operations Chief for the City of Costa Mesa, and Fire Chief for the Cities of Fullerton and San Clemente, California. He was the Operations Chief for the Costa Mesa Fire Department and has served in both the United States Forest Service and U.S. Park Service. He has served in the fire service for 43 years.

He possesses a Masters of Arts Degree in Vocational Education from Cal State Long Beach, a Bachelors of Science Degree in Political Science from Cal State Fullerton and an Associate of Arts Degree in Fire Science from Rancho Santiago College.

He has served in many elected positions in professional organizations, including President, International Association of Fire Chiefs, Vice President, International Committee for Prevention and Control of Fire (CTIF), and President, California League of Cities, Fire Chiefs Department. He has held professional memberships in many other organizations, such as the International Association of Fire Chiefs, International Fire Code Institute, Conference of Building Officials, National Fire Protection Association, and the Institution of Fire Engineers, USA Branch. He was elected as a Fellow of the IFE by the British Chapter.

His experience includes progressive responsibilities for creating or implementing fire protection policy from the local, state and national levels. Besides regular day to day duties he has served as Chairman of the IAFC Fire and Emergency Services Accreditation Task Force, Chairman of the NFPA Committee on Motion Picture and Television Production (NFPA Standard number 140), Chairman of the Risk, Hazard and Value Evaluation project (RHAVE), U.S. Fire Administration, Chairman of the IFCI for the creation of Urban-Wildland Interface Code Committee, a member of the Oversight Committee for the National Institute of Standards and Technology (NIST), and member of a consensus committee for Liquefied Petroleum Gas Negotiated Rule-making for the U.S. Dept of Transportation, and Chairman of the Orange County Emergency Medical Services Committee. He has authored over 12 textbooks on fire and emergency related topics.

He is the current Chairman of the Board of Trustees for the Commission on Fire Accreditation International (CFAI). Governor Schwarzenegger appointed him to the Blue Ribbon Panel to study the fires of 2003.

\section{Kathleen M. Higgins}

Kathleen M. Higgins' career in criminal justice and public safety began soon after she earned her B.S. in chemistry from the University of Rhode Island. As a freshman toxicologist in the state's Department of 
Health, she was assigned to analyzing evidence submitted by police detectives, medical examiners, even the horse racing commission. She found the work challenging and in the years that followed earned a Masters degree in Forensic Chemistry at Northeastern University, did course work at Brown University in the fields of drug abuse and medical-legal autopsies, and co-founded a private forensic laboratory in Boston. She also lectured at the Massachusetts Criminal Justice Training Center and at Northeastern University, where she was made coordinator of the graduate and undergraduate forensic programs.

She earned a Meritorious Service Honor Award for her efforts, but public safety and criminal justice remained her passion, and in 1994 she accepted an invitation to serve as Director of the Office of Law Enforcement Standards (OLES) at the National Institute of Standards and Technology (NIST).

Under Ms. Higgins' leadership OLES has grown from a handful of programs with a budget of $\$ 1.1 \mathrm{M}$ to more than 50 active projects and a budget of about $\$ 40$ million. She has been widely recognized for her efforts. In 2001 NIST's parent agency, the Department of Commerce, awarded her its Silver Medal for Outstanding Achievement. And in 2002 George Washington University honored her with the prestigious Arthur S. Fleming Award for her extraordinary service to the Federal Government and the nation. She currently serves as the Assistant to the Director for Homeland Security and Chair of the Homeland Security Strategic Working Group at NIST.

Ms. Higgins is the author of several forensic science journal articles, a Fellow of the American Academy of Forensic Sciences, Past President of the Massachusetts Chapter of the International Association of Arson Investigators, and a member of several professional organizations, including the ASTM International E-54 Committee on Homeland Security Applications (Chair), the ASTM International E-30 Committee on Forensic Science (Recording Secretary), the International Association for Identification, the International Association of Bomb Technicians and Investigators, the National Fire Protection Association, and the International Association of Chiefs of Police.

\section{Joel Leson}

Col. Leson works for the Department of Defense (DOD) having served 26 years in the Army and attaining the rank of colonel prior to joining the Office of Inspector General (OIG) DoD, in 1991. He is a member of the Federal Government's Senior Executive Service. Mr. Leson holds a Bachelor of Science Degree in Political Science and Business Administration from Temple University and a Master of Science in Forensic Science from The George Washington University. He is a graduate of the Federal Bureau of Investigation National Academy (88th Session), the Federal Executive Institute and the US Secret Service Protective Operations Course. He was a Senior Research Fellow in National Security at the John F. Kennedy School of Government, Harvard University. Among his Army assignments, he commanded the US Army Criminal Investigation Laboratory and US Army Criminal Investigation Command's Second Region (Europe). He was the Assistant Inspector General for Criminal Investigative Policy and Oversight for the OIG, DoD, and is currently assigned to the International Association of Chiefs of Police to deal with weapons of mass destruction and counter terrorism matters, with emphasis on personal protective equipment for law enforcement personnel.

\section{Donald O. Hewitt, CISSP}

Mr. Hewitt is a Principal Consultant for Proconsul, Incorporated, and a Certified Information Systems Security Professional. He is also the TRC Program Manager for the Project Responder Knowledge Base, which will provide a trusted source of equipment-related information to the emergency responder and 
homeland defense community. He has more than thirty years' experience in a variety of technical and management disciplines. He received a Bachelor of Science Degree in Management Science from the Massachusetts Institute of Technology, and a Master of Science Degree from the Sloan School of

Management, also at MIT. As a Distinguished Military Graduate, he received a commission in the U.S. Army, where he served for five years. He subsequently held both operations and program development positions at Computer Sciences Corporation, Storage Technology Corporation, and Network Solutions, Inc. He also co-founded Security Design International, a network security consulting firm. He served as SDI's president until its acquisition, after which he returned to private consulting with Proconsul. His security consulting clients have included both commercial clients and Government organizations such as the National Institutes of Health and the Federal Aviation Administration. Mr. Hewitt is also a private pilot with multiengine and instrument ratings. He was named to the TRC Board of Directors in 2002, and serves as secretary of the corporation. 


\section{Appendix F - An Example Scenario Using an Incident Command Tactical System}

This scenario is illustrative only. It was provided by Captain Gary Wedemeyer of the Fresno, California Fire Service, and is based on the pre-plan discussion paper in Appendix C. It does not reflect an actual incident, but rather how new display concepts might be utilized in emergency response.

\section{Displaying information received from the Incident Command Technology System}

How we display the static and dynamic information that is received from the Incident Command Technology System (ICTS) is of the utmost importance. Simplicity cannot be stressed enough. The most important thing to keep in mind, is where this information will be viewed. In all cases, it will be on a small screen that is attached to a vehicle that will be traveling at a high rate of speed, in poor lighting, and with lots of bumps.

As in Appendix C, "static" means anything to do with a building that, for the most part, does not change and "dynamic" will refer to anything that does change within a building when an emergency occurs.

This example will walk you through the response, the arrival, and the after arrival scene. I will demonstrate with text and visual aids how I think this system could be displayed in a way that will greatly enhance the information given to those that are most critical to the overall outcome of the emergency scene -- the First Responders.

Getting this information in a timely matter is very important. Responding to an incident in a building provides a few minutes to absorb any static or dynamic information about the scene. An example of timing for most vehicles:
Initial call
1 minute
No information
2 minute
Put on personal protective gear - worst time to convey building information
3 minutes
Climbing into engine, being seated and belted - better
4 minutes
Using the GIS map and display to navigate and plan - is it a smart building?
5 minutes
Monitoring proper route - best time to see additional information
On scene
Arrival - initial size up; Only show assessment of the problem - no details
Start SOP (sequence of procedure??) - assessment, deploy hoses and ladders if needed

An example of timing for single rider vehicles ${ }^{1}$.
Initial call
1 minute
No information
2 - 3 minutes
Into vehicle, all systems on - only time for error checking
4 minutes
Drive to scene - GIS map and simple audio is all that is available
Arrival - face to face and establish communication
5 minutes
Initial command set up. - now is the best time for additional information

\section{High Rise Fire Scenario}

For this example, we will respond to a 7 story, 24 hour care facility that has a disgruntled tenant who decides to burn the building down. It is a high rise building. He will start by shutting down the sprinkler system to the building, and then light multiple fires on the $5^{\text {th }}$ floor.

This type of call would require police, fire, and EMS to respond. The following timeline and details of the information system are given from the perspective of the first fire engine to arrive.

0345: Initial dispatch: Fire alarm at $1730 \mathrm{~W}$ Shaw. No further information.

0345-0346: Crew members get to the fire engine and place their personal protective equipment on.

\footnotetext{
${ }^{1}$ It is always assumed that all field supervisors of both police and EMS drive alone in their cars.
} 
0346-0347: After getting seat belts fastened, the captain informs dispatch that $\mathrm{E} 1$ is enroute. He then has to direct his attention on how to GET to the call. He looks at the mobile data terminal (MDT) and switches to the "map". The map is nothing more than digitized layers that are geo-referenced. In Fresno, on our map, set to be invisible, is a layer that consists of points. There is a geo-referenced point for every address location in the city. The software on our MDT searches out those points to find the one that belongs to the address we are responding to. It then places an "Event location" symbol directly over that dot.

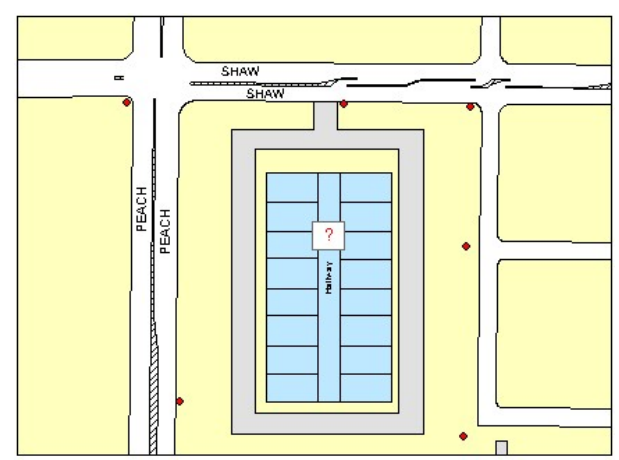

Initial display on MDT.

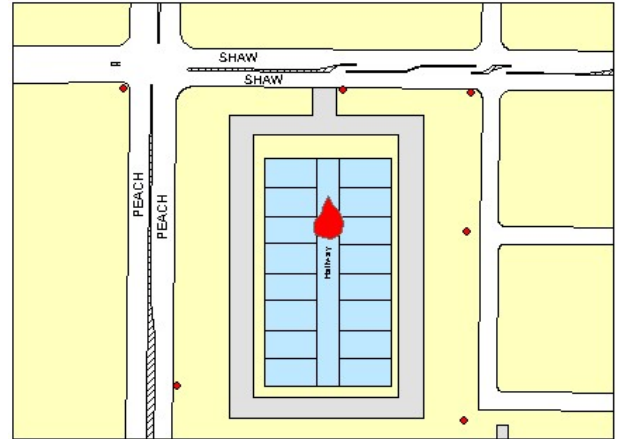

Pressing query symbol might show an issue with body fluids

In Fresno's case that symbol is a yellow triangle. In the figures above, we see what Fresno's Fire map would look like. The Building is blue, the hydrants are red dots, and the driveway is grey.

0347 Hours: Dispatch informs E1 that they are receiving phone calls from the building stating that there is someone inside the building screaming and setting fires. This means dispatch would automatically start a full alarm to the site. They would also get Police and EMS dispatched as well.

0347-0350 hours: Upon looking at the map, the captain sees that the Event locator symbol is a white square with a question mark in it. He knows this means they are responding to an ICTS smart building.

Selecting the white rectangle brings up further information as seen in the following figure ${ }^{3}$ :

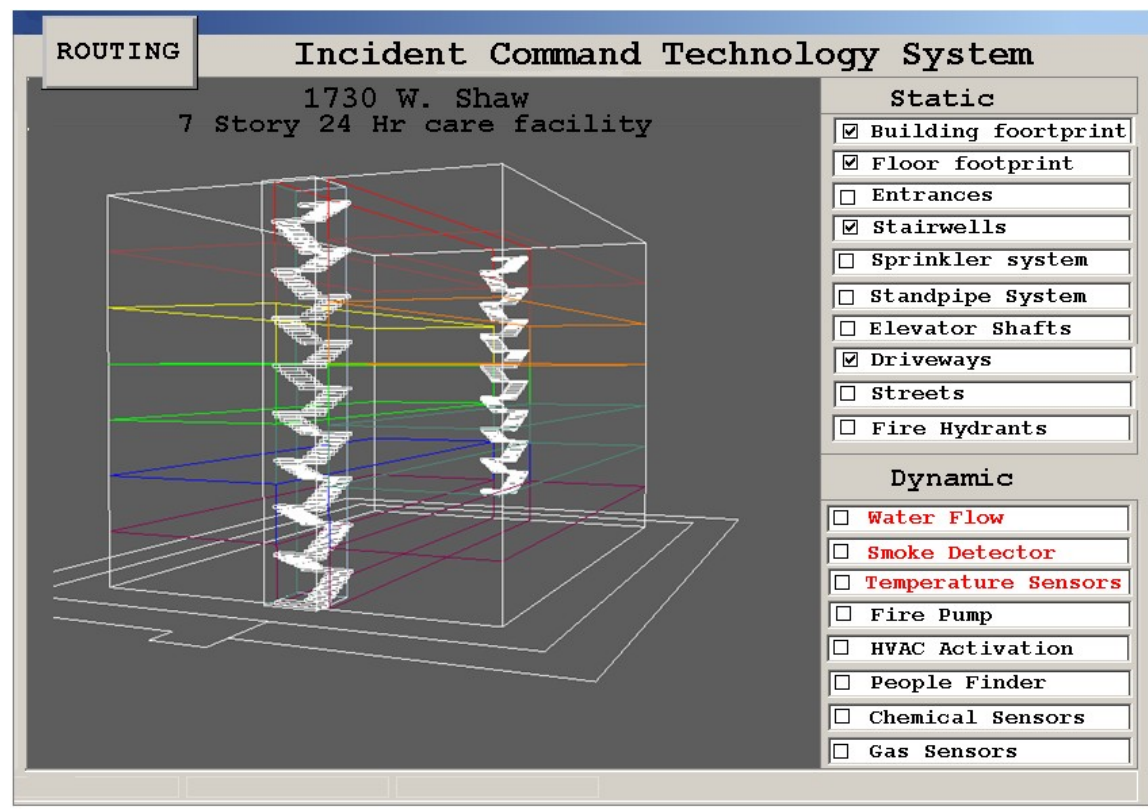

${ }^{2}$ An event location symbol signifies that additional information is available - see text for suggested icons

${ }^{3}$ Color coding: red is used to indicate dynamic data which has changed from the initial value (level). 


\section{Notes on using the MDT}

When additional information is available, it needs to be VERY easy to access. Another critical aspect that will need to be worked into the system is the ability to get back to the "Routing" map that they will be using to get to the scene. Note the ROUTING button and its prominent display.

During these two minutes that the Captain has to look up any additional info on the building, he still has to guide his driver to the scene. There are many times when traffic, or trains, or even the driver missing a turn, make it necessary to adjust the route, and that requires IMMEDIATE access to the routing software. This cannot be stressed enough. If the system does not get back to the routing easily, it will not be used.

It is assumed that the additional information can be found by simply clicking on the "Event locator symbol"-- the white box, located on the routing portion of the software. This will launch into a display that will have three sections. A 3D picture of the building in question that can be grabbed and moved and rotated, a drop-down window that will have a list of all STATIC layers available for this building, and a drop-down list of all DYNAMIC layers to the building.

0347 Hours: The Captain on Engine one notices that the Event locator symbol on his routing map is a white square. He clicks on this white square, and that causes his MDT to launch into the software that will display the additional information from the ICTS.

\section{Notes on using the MDT event locator}

As you look at the 3D portion, remember that you will be able to grab this model and rotate it in all directions. Even as a $2 \mathrm{D}$ picture, it is still quite easy to see what type building we have.

This is an example of the opening screen to the ICTS. As can be seen, on the right hand side are lists of Static and Dynamic sections of the building. The software can be set to automatically display a minimum amount of info initially. Depending on who is using the MDT (EMS, PD, FD ) you can tailor the initial screen to their needs.

If the individual using the MDT wants to see more of the Static or Dynamic info, it is only necessary to place a checkmark in the box next to that item, and it will appear. Displaying the info in this manner gives the user the ability to look at as MUCH or as LITTLE as needed, without overloading the screen.

NOTE: The items in red in the "Dynamic" section. They are red because something has changed in the building and put these systems in alarm. Just by turning red, they already begin to paint a picture.

\section{Notes on the initial display:}

Note the large black text on the 3D picture itself that gives an address and a very brief Building type description. It doesn't necessarily need to be on the 3D portion, but it needs to be somewhere on the screen in big font--- Address and a BRIEF description.

As a first responder, just looking at this initial screen gives me a wealth of knowledge without making anything else visible. I know the address. I know how big the building is. I know what systems are in alarm. I know how many stairwells there are to get in. Showing an elevator bank would be good on this initial screen as well. A North direction arrow would also be good.

0347-0348 Hours: After looking at the additional initial information, the Captain decides to look at some of the other layers of info available while enroute. In this case, he is going to look at some of the dynamic info that has been highlighted in red.

\section{Notes on layers}

As can be seen by the display I made up here, you simply place a checkmark in the box next to the info you want to see.

Note: most displays do NOT have a mouse. We will be doing all screen manipulation with fingers. Please make the field that activates that checkmark LARGE. In this case, if I touch anywhere within the box that has the text for that layer, it will turn it on or off. 
The display below shows what the Heat sensors could look like on the screen. Each heat sensor would be responsible for a block of that building, and it would color code that block to reflect the amount of heat in it. Rather than just giving me text that says "Heat sensor on the $5^{\text {th }}$ floor reads 897 degrees", show me the info in color coded blocks of the building.

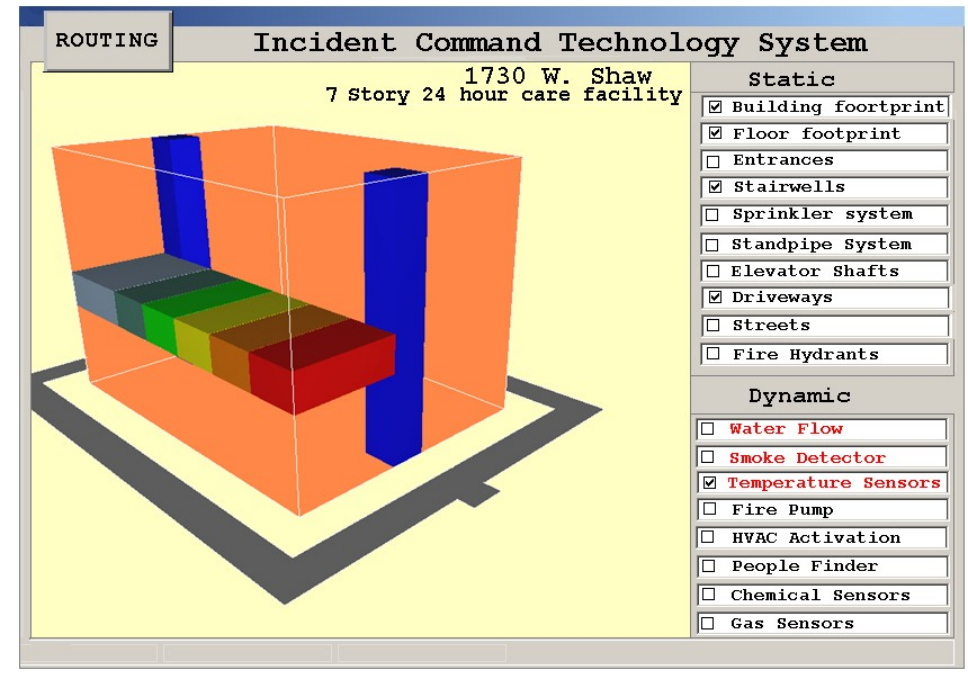

A nice thing to add here would be text that attaches to these heated blocks that ONLY tells me the floor that they are on. If Red is hot, it is very easy for me to see where this fire started.

Here we have rotated the display around to get a look at all sides. ONLY the Heat sensing Blocks that register ABNORMAL heat will display. As we refresh this view, we can see that the fire has breached one stairwell and spread heat and possibly fire to the top floor.
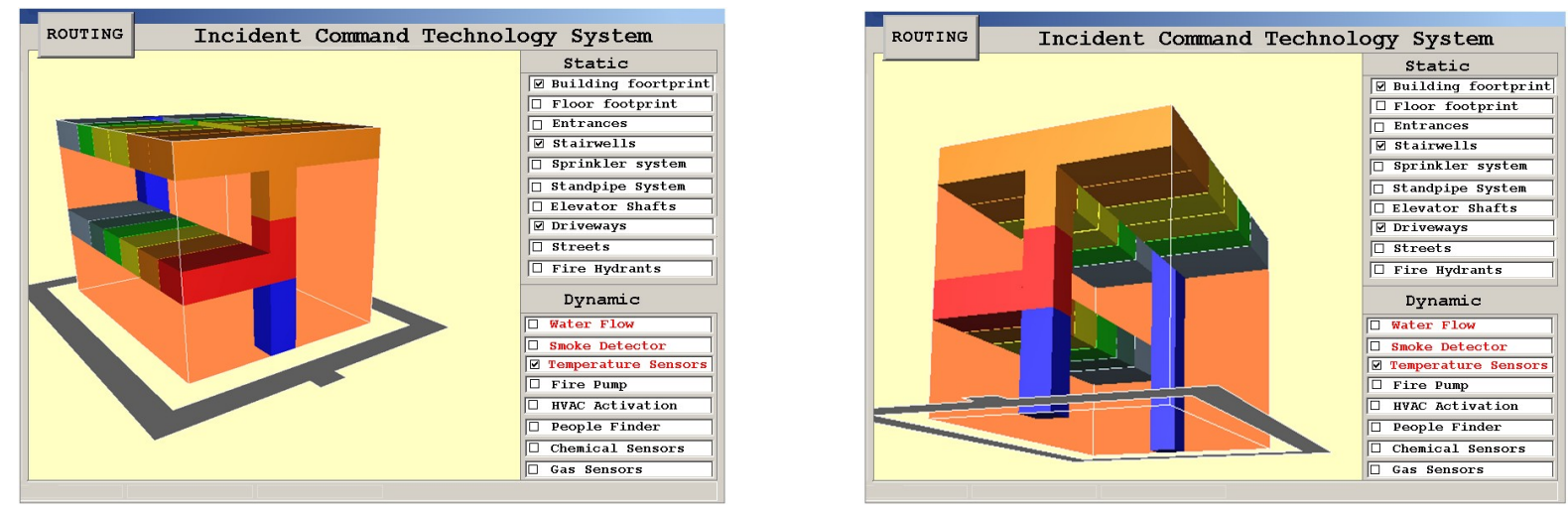

As is stands now many departments, when only a fire alarm from a building is received, send a single engine to check it out. Upon arrival, if there is fire or smoke, dispatch is called to bump up the alarm to a "Full Response." That simply means, get all the fire apparatus rolling that would have been dispatched if it had been reported as an actual fire. Having active building data would preclude this step, saving a great deal of time.

There are many advantages to this ICTS system when it becomes reliable. If this info is transferred wirelessly to our rigs, and to our dispatch center, I can see it changing how the initial response would be. If the personnel at dispatch saw this picture, they would start a full alarm response from the beginning.

Furthermore, I, as the first in captain could initiate a $2^{\text {nd }}$ or $3^{\text {rd }}$ alarm on this fire, just based on what the ICTS has shown me PRIOR to my arrival. Getting the right amount of resources to an emergency as quickly as possible is one of the most crucial aspects to successfully dealing with an emergency. 


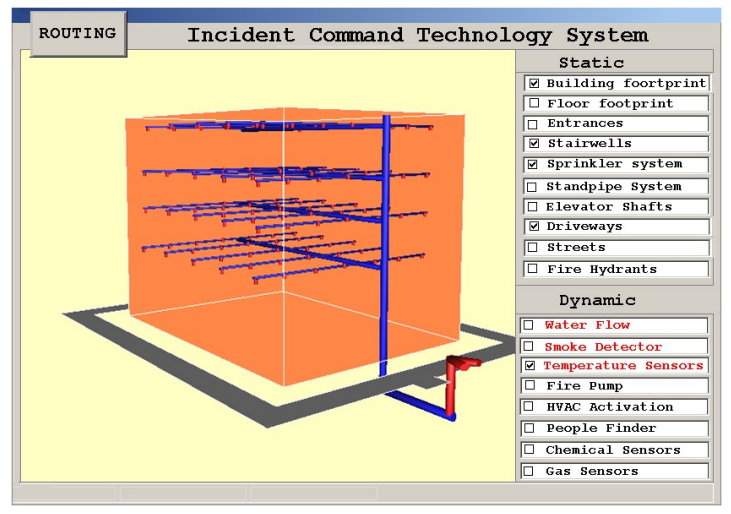

$3 \mathrm{D}$ view of the building sprinkler system (piping)

0348-0349 Hours: The Captain decides to look at other information. In this case, he wants to see what fire suppression systems are available to deal with the fire. The piping diagram displays the sprinkler distribution system.

\section{Notes on building displays, thermal imaging and video on scene}

Standpipe: Here we have a display of the stand-pipe connection and which stairwell it supports.

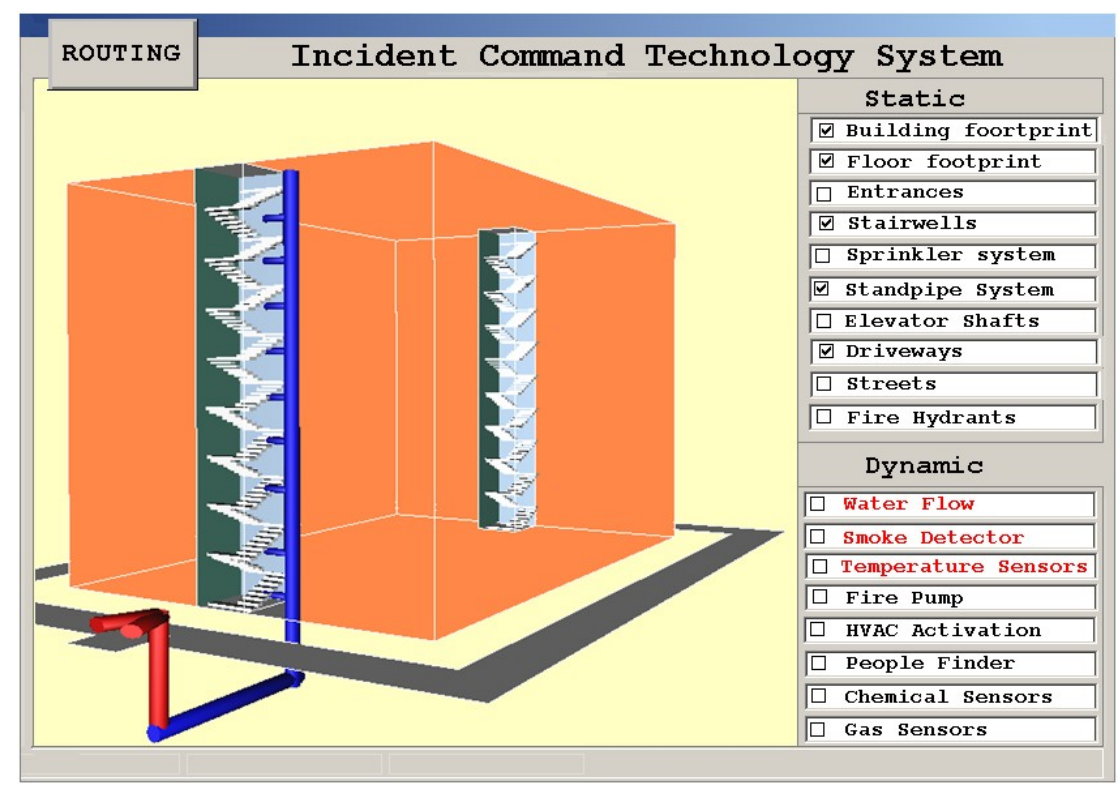

It does clearly show which stairwell it supplies, where the hook-up is, and which floors it goes to.

Cameras and thermal imaging: Seeing a thermal image, or seeing an actual camera view is only half the battle. Law enforcement will use cameras in their situations as a tremendous tool. In fact their ICTS system ought to be designed around that for them.

However, as far as the fire department is concerned, there could be a more useful display of this type information. If it is a fire we are talking about, then there are two basic pieces of knowledge that are needed: where the fire is, and where the people are that need to be rescued.

The heat sensors, smoke detectors, and water flow sensors can pretty much tell us where the fire is. A camera on the fire floor or any floor with smoke in it, will be useless. A thermal imager would be nice, but, keep in mind that a thermal imager, on the fire floor, will most likely show solid white because it will be at the ceiling level where all the heat will be. 
Even if one assumes that this smart building will have thermal imagers in every room, and hallway, and stairwell in the building, it would be necessary to tap into each individual imager to see what was where and be certain of the area you are looking at.

Occupant location: If there were technology to locate occupants as well as responders, then one could use the technology today to make "people finders", for lack of a better term. It could combine info from thermal and heat sensors to identify heat signatures that most likely are that of a human. Then there would be an icon placed on the MDT's 3D image to show where this body is.

No matter what type of imager or sensor, whether it is heat, gas, or chemical, the best way to display what it sees would be in blocks of the 3D building. If the ICTS senses chemicals, don't just provide text. Use the 3D image to show ONLY the blocks of the building that are affected, and then attach text to describe what it has found.

0349-0350 Hours: After looking at the various layers of the ICTS system, the captain decides to take a quick look at the "People Finder" before arrival.

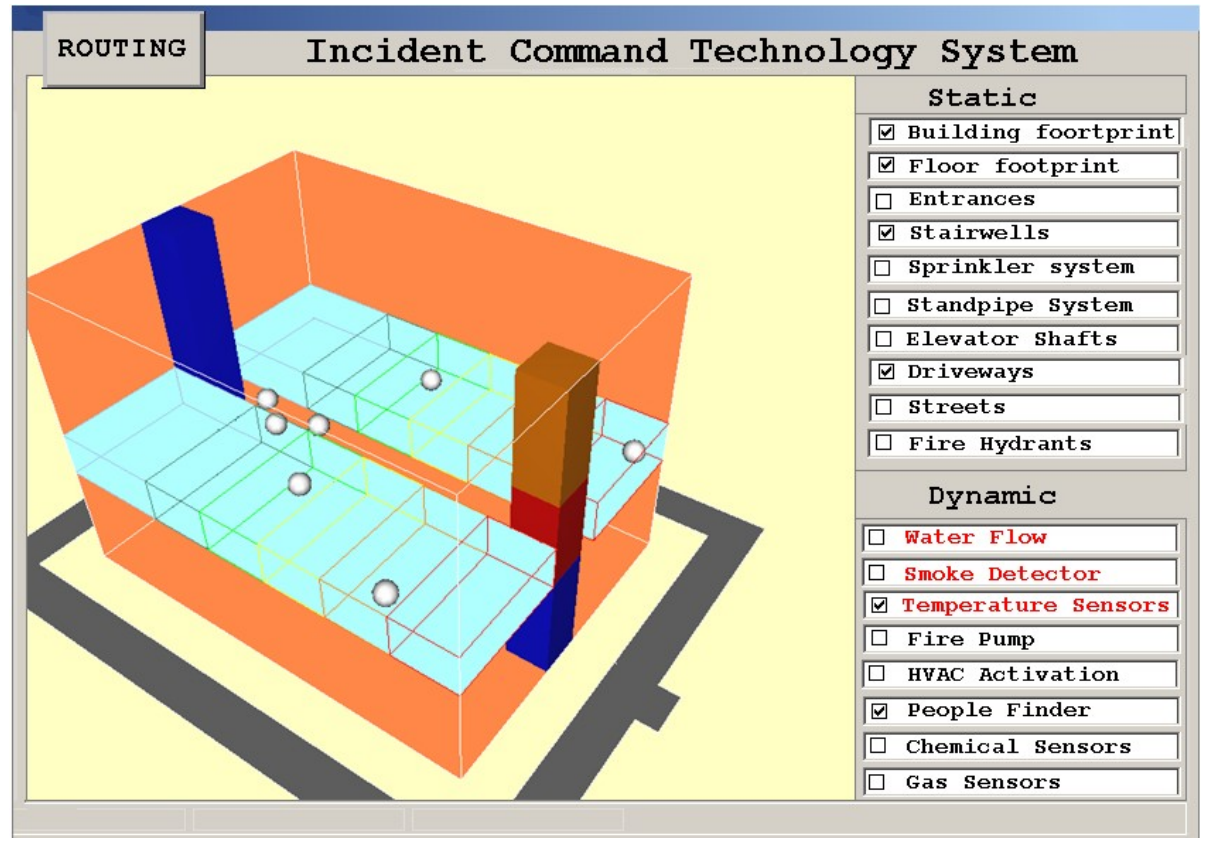

This can gives a quick visual on whether or not there are victims that need to be rescued and where they are.

\section{Notes on the MDT}

One could take this a step further, and place a red dot on the floor to show where all firefighters are, because they will be wearing personal locators that the ICTS system can track. The white dots are victims and the red dots (not shown) are first responders.

Viewing data such as this, or any other moving variable, whether it is heat, gas, chemical, or people, if you display it in this 3D manner it becomes easier for us to use. If we did go this route, we would need to be able to look at it on a floor by floor basis. When I click on people finder, a drop down menu can pop up and ask which floor I want, or it can show me all at once if I so desire. This would be true for any other sensor as well.

Whether I was searching for victims, or law enforcement was searching for a criminal moving through a building, this type of picture for what the imagers are finding would be of great value. It would also prevent the need to tap into NUMEROUS cameras and imagers. (Please see the notes on HIPPA and privacy in the workshop summary.)

\section{Hours:}


Engine One arrives. The Captain is immediately approached by numerous people. Some are relatives of victims inside the building, some are uninvolved pedestrians, and some may be building officials from whom we need to get critical information.

There will be very little access of the ICTS by the first on scene unit after they arrive.

\section{Examples of chaos on scene}

Police: First unit on scene to a domestic disturbance, guns involved, fifth floor. Does this PD officer have time to sit in the front seat after arrival and check the ICTS?

EMS: First unit on scene to a domestic disturbance, guns involved, two gunshot victims, one of which is now a police officer on the fifth floor. Does this Paramedic have time after arrival to look at info on the ICTS?

Field supervisors show up after the first responders have been there for several minutes. They are tasked with setting up a permanent Incident Command Post. They have time to look at additional info on the ICTS system AFTER arrival.

By giving first responders the capability to turn on and off layers of information, there is access to as much or as little information as wanted. If the ICTS is to be of any value to the first arriving unit, it needs to be available to that unit so they can look at it prior to arrival. And the information transfer needs to be appropriate to the responder, either audio or graphic.

\section{Making it a system that can be used by multi-jurisdictions}

This is a difficult issue to solve. Different jurisdictions find different GIS solutions. These do not work with each other in many cases. When an ICTS is going to be of the most value to us is when the big disaster hits. And when the big disaster hits, there will be multiple agencies present. I know that it is not likely that we can achieve national regulations specifying that ALL Fire, Police, and EMS shall use the same software company to design its GIS, ICTS compatible system.. However, perhaps you could entertain the thought of regulating the format that all these various companies produce their digitized geographical coverage's, so that they at least would be compatible on any MDT in the nation, regardless of who built the MDT, or wrote the software that runs computer aided dispatch or automatic vehicle location on the respective MDT.

In other words, If Fresno City builds a layer that shows 3D images of buildings in its jurisdiction, using ESRI software, an engine responding from Clovis City should be able to display that same digital picture on its MDT that uses software designed by FirePro. It certainly would be nice if a fire engine or police unit responding out of jurisdiction had access to all the GIS and ICTS data from that jurisdiction. Perhaps once that unit falls under the umbrella of the new jurisdiction, the ICTS and GIS info would be sent to the MDT. 